\title{
CORPO E NARRATIVA NA GRÉCIA CLÁSSICA
}

Helena Miranda Mollo

Universidade Federal do Rio de Janeiro

Resumo: Este artigo tem como objetivo estudar a relação entre a Medicina e a História no $V$. século grego. Esta relação é estudada em duas narrativas: no Tratado Sobre a Natureza do Homem e na Historia da Guerra do Peloponeso. Nestas narrativas nós estudamos as ligaçôes entre alguns conceitos como a doença no corpo humano e a guerra.

Palavras-chave: Medicina Antiga; Narrativa; História; Documento.

0 estudo do corpo como objeto histórico para J.P. Peter e J. Revel ${ }^{1}$ antes mesmo de ser inovador, possui o papel de fazer retornar este "objeto de estudo" para o historiador.

Resgatado em parte pela História das Ciências, o estudo do corpo ganha uma perspectiva mais ampla a partir das obras de Michel Foucault ${ }^{2}$. Visto por este autor sob a ótica da sexualidade, fornece explicações em múltiplas faces da vida social. Desta forma, vemos que no corpo há uma narrativa própria e esta revela uma sistematização do mundo.

Inumeráveis são as narrativas que envolvem o corpo na Grécia clássica. Ao mesmo tempo em que é objeto de estudo, o corpo transforma-se num modelo de descrição para a sociedade.

Em duas narrativas em particular esta relação mostra-se flagrante: a Medicina e a História; os textos que revelam essa proximidade são os tratados médicos Sobre a Natureza do Homem e a Antiga Medicina. No discurso histórico a narrativa da Guerra do Peloponeso de Tucídides. Os tratados médicos aqui relacionados pertencem ao Corpus Hippocraticum, ligados à Escola Médica de Cos, na costa jônica. Estes escritos não possuem um autor apenas, mas podemos situar como elo de ligação entre eles, o recorte temporal que também os liga ao contexto da Guerra do Peloponeso.

A partir do século VI A.C. estes discursos em prosa buscam uma descrição objetiva de seus respectivos objetos. A objetividade para os autores dos tratados médicos e em certa medida também para Tucídides está relacionada à observação. É desta forma que a Medicina representará um modelo para a narrativa da Guerra do Peloponeso.

M. Finley em seu artigo Tucidides, o Moralista propõe uma questão ao historiador grego: "Como se faz para escrever a história de uma guerra longa?" (Finley, s/d, p. 60) Como resposta encontramos na obra de Tucídides a proposta de

1. PETER, J. P. e REVEL, J., 1988, p. 141-160.

2. FOUCAULT, M. História da Sexualidade. Rio de Janeiro: Ed. Graal, 1985, 3 vols 
uma narrativa afastada dos discursos míticos anteriormente utilizados, o uso de um calendário próprio àquele acontecimento, para que assim se transformasse num texto que narrasse todas as guerras. A introdução de apenas duas estaçōes inverno e verão - seria uma primeira sistematização dos acontecimentos. Neste aspecto Tucídides se afasta da narrativa histórica que o precede e toma parte de uma nova forma de abordar a história. Finley ainda nos lembra que é neste aspecto que os tratados médicos da Escola de Cos são seu paralelo.

O Tratado Sobre a Natureza do Homem e a Antiga Medicina propõem que a observação e, em alguma medida, a experiência sejam o ponto de partida para a definição do Homem. Neste caso, reivindicam um limite próprio para a Medicina a propósito do que venha ser 0 corpo humano, a saúde e a doença. Assim, nos diz 0 Tratado Sobre a Natureza do Homem.

... Quem quer que tenha o hábito de escutar as exposições sobre a natureza humana que saem do estrito domínio da Medicina não tem nenhum interesse em escutar a presente exposição ...

A observação também inicia a narrativa histórica de Tucídides, pois 0 historiador utiliza constantemente este recurso, tentando abranger todos os movimentos da guerra:

$\therefore$ Via que ambas as partes estavam preparadas em todos os sentidos, além disto observava os demais helenos aderindo a um lado ou ao outro ... 4

Tucídides segue sua narrativa "pesquisando" todos os indícios que, juntos, caminharam para esta "desproporção" que é a guerra. Esta "pesquisa" iniciase com a própria formação da Hélade que o historiador tenta fazer, afastando-se da narrativa mítica. A este respeito, Tucídides afirma:

... Segundo minhas pesquisas, foram assim os tempos passados, embora seja dificil dar crédito a todos os testemunhos nesta matéria. Os homens na verdade, aceitam uns dos outros relatos de segunda. mão dos eventos passados, negligenciando pó-los à prova, ainda que tais eventos se relacionem com sua própria terra ...5

0 inventário proposto por Tucidides através da observação e da pesquisa sugere que a verdade sobre a guerra pode ser alcançada por meio de um percurso que the é próprio.

De forma análoga, as narrativas médicas afirmam que o homem possui uma natureza própria, imutável e inconfundível com quaisquer outras. 0 Tratado Sobre a Natureza do Homem apresenta em seus primeiros passos a seguinte

3. HIPPOCRATE, trad. JOUANNA, 1975, p. $165(1,1)$.

4. TUCIDIDES, trad. KURY, 1977, $(1,1)$.

5. Ídem, $(1,20)$. 
questāo: de que é composto o corpo humano? Pela via da observação 0 autor afirma:

... O corpo do homem é repleto de sangue, flegma, bile amarela e a bile negra e. estes mesmos são a natureza do corpo, da doença $e$ da saúde ...6

Ainda segundo 0 autor, cada um destes humores possui uma característica própria e imutável. A transformação que pode sofrer cada um deles será sempre a da proporção e nunca da sua "natureza". Partindo desta primeira definição, o Tratado afirma que a ligação entre a saúde e a doença é o resultado da proporção destes humores:

... Nestas condições, há saúde perfeita quando estes humores estão numa justa proporção entre eles, do ponto de vista da qualidade $e$ da quantidade e quando sua mistura é perfeita. Há doença quando um desses humores em pequena ou grande quantidade se isola no corpo, em vez de estar misturado a todos os outros ...7

A necessidade de observação para se fazerem as definições se faz presente quando 0 autor chama a atenção para 0 aspecto dos humores. São estas diferenças que também irão determinar os seus nomes e usos.

... Segundo o uso, os humores têm nomes distintos e alguns entre eles não possuem o mesmo nome. Em segundo lugar, de acordo com a Natureza eles têm um aspecto radicalmente diferente. Oflegma não se assemelha ao sangue, nem o sangue d bile, nem a bile ao flegma. Como, em efeito, os humores poderão se parecer, eles que não oferecem nem a mesma cor à vista, nem mesma sensação ao tocar? ...8

Na definição de doença e de saúde, os tratados médicos fornecem um modelo que foi seguido por Tucidides para narrar a Guerra do Peloponeso. Ao enfatizar o papel que cada humor exerce no corpo humano, os tratados afirmam que a doença vem do desequilíbrio de cada um deles. Esta desproporção pode derivar ou do aumento, ou da diminuição da quantidade dos humores ou do isolamento de um deles no corpo. Podemos ver que neste tratado, a doença nã̉o é vista mais a partir da ira divina e sim do próprio corpo. É a partir dessa imagem que Tucídides constrói sua narrativa, pois de maneira análoga ele estabelece que uma desproporção foi a causa da Guerra do Peloponeso. As duas ligas que se formaram para a Guerra causaram o conflito das outras partes da Hélade. Assim, narra Tucídides:

6. HIPPOCRATE, trad. JOUANNA, 1975, p. 173 (IV, 2).

7. Idem, p. 173-5 (IV, 2-3).

8. Ibidem, p. $177(\mathrm{~V}, 2)$. 
... Mas agora que as duas alianças estavam em guerra, cada facção nas várias cidades, se desejavam uma revolução, achava fácil recorrer a aliados (...) Dessa forma, as revoluçóes trouxeram para as cidades numerosas e terriveis calamidades, como tem acontecido e continuará a acontecer enquanto a natureza humana for a mesma ... 9

De forma análoga, também a peste em Atenas será narrada. Aliada à guerra ou provocada por esta, a doença assola a todos indiscriminadamente tornando a cidade apolitica.

J. P. Peter e J. Revel no artigo 0 Corpo. 0 Homem Doente e sua História ${ }^{10}$ vêm que a Medicina em seu início ligava-se apenas à experiência singular do doente. Os autores destacam que nas crônicas de Tucídides a Gregório de Tours a doença (epidemia) é uma "passagem obrigatória". (Peter, J. P. e Revel, J., 1988, p.142) e apesar de coletiva é "assinalável sobre um único indivíduo" (ídem).

Aceitando em parte essa perspectiva, vemos que na narrativa de Tucídides seja em relação ao coletivo, seja em relação à cidade de Atenas, a epidemia transtorna todos sem qualquer distinção. A imagem do corpo e da doença feita pelo Tratado Sobre a Natureza do Homem revela-se aqui importante para 0 discurso histórico. Tucídides toma a cidade como um corpo e, no caso, é ela que fica doente. É ela que sofre com os movimentos "desproporcionais" provocados pela guerra. Assim, em funçã̃o dessa desproporcionalidade, o interior do corpo social uma vez atingido torna-se doente e com isso apolítico.

0 singular a que se referem J. P. Peter e J. Revel possui portanto dois lados. Além de falar do indivíduo, a coletividade torna-se corporificada para ser narrada pelo historiador.

Mais uma vez ligando as duas narrativas - os tratados médicos da Escola de Cos e a Historia da Guerra do Peloponeso de Tucídides - que nos propusemos comparar brevemente, podemos verificar que ambas narram uma história: de um lado, a medicina narra a história desse corpo individual e ao mesmo tempo coletivo, pois fala de uma natureza humana; de outro lado, a história de Tucídides fala de um corpo que é político e que possui uma formação (tradição) e uma constituição. Tal como um corpo deve ter uma justa proporção de todos os seus elementos formadores.

Vimos que o corpo possui uma narrativa, ou antes, narrativas, que ele propõe inúmeros discursos. Da sua imagem articulada não surge apenas um vocabulário objetivo para o historiador do Vo século a. C., mas uma distribuição e organização para uma narrativa da trajetória e da vida das cidades.

\section{Bibliografia}

BRATESCU, G. Le Probleme de la Mesure dans la Collection Hippocratique. In. La Collection Hippocratique et son rôle dans l'Histoire de la Medicine. Leiden: G. L. Brill, 1972. 
Cambiano, G. Pathologie et Analogie Politique. In. La Collection Hippocratique et son róle dans l'Histoire de la Medicine. Leiden: G. L. Brill, 1972.

FINLEY, M. Aspectos da Antiguidade. Lisboa: Ediçōes 70, s/d.

FOUCAULT, M. Historia da Sexualidade. Rio de Janeiro: Ed. Graal, 1985, 3 vols.

GRMEK, M. O Homem Biológioco no Mediterrâneo. In. BRAUDEL, F. Uma Lição de História. Rio de Janeiro: Jorge Zahar, 1989.

PETER, J. P. e REVEL, J. 0 Corpo. 0 Homem Doente e sua Historia. In: LE GOFF, J. e NORA, P. (orgs). História: Novos Objetos. Rio de Janeiro: Ed. Francisco Alves, 1988, p.141-160. 